\title{
Bid-induced release of AIF from mitochondria causes immediate neuronal cell death
}

\author{
S Landshamer ${ }^{1}$, M Hoehn ${ }^{1}$, N Barth ${ }^{2}$, S Duvezin-Caubet ${ }^{3}$, G Schwake ${ }^{4}$, S Tobaben ${ }^{5}$, I Kazhdan ${ }^{6}$, B Becattini ${ }^{7}$, S Zahler ${ }^{2}$, A Vollmar ${ }^{2}$, \\ M Pellecchia ${ }^{7}$, A Reichert ${ }^{3}$, N Plesnila ${ }^{\star, 8,9,10}$, E Wagner $^{1}$ and C Culmsee ${ }^{\star, 1,11}$
}

Mitochondrial dysfunction and release of pro-apoptotic factors such as cytochrome $c$ or apoptosis-inducing factor (AIF) from mitochondria are key features of neuronal cell death. The precise mechanisms of how these proteins are released from mitochondria and their particular role in neuronal cell death signaling are however largely unknown. Here, we demonstrate by fluorescence video microscopy that 8-10 h after induction of glutamate toxicity, AlF rapidly translocates from mitochondria to the nucleus and induces nuclear fragmentation and cell death within only a few minutes. This markedly fast translocation of AIF to the nucleus is preceded by increasing translocation of the pro-apoptotic bcl-2 family member Bid (BH3-interacting domain death agonist) to mitochondria, perinuclear accumulation of Bid-loaded mitochondria, and loss of mitochondrial membrane integrity. A small molecule Bid inhibitor preserved mitochondrial membrane potential, prevented nuclear translocation of AIF, and abrogated glutamate-induced neuronal cell death, as shown by experiments using Bid small interfering RNA (siRNA). Cell death induced by truncated Bid was inhibited by AIF siRNA, indicating that caspase-independent AIF signaling is the main pathway through which Bid mediates cell death. This was further supported by experiments showing that although caspase-3 was activated, specific caspase-3 inhibition did not protect neuronal cells against glutamate toxicity. In conclusion, Bid-mediated mitochondrial release of AIF followed by rapid nuclear translocation is a major mechanism of glutamate-induced neuronal death. Cell Death and Differentiation (2008) 15, 1553-1563; doi:10.1038/cdd.2008.78; published online 6 June 2008

Progressive degeneration and death of neurons are the major features of several acute and chronic neurodegenerative diseases such as ischemic stroke, Alzheimer's disease, or Parkinson's disease. ${ }^{1}$ The main mechanisms of neuronal cell death are, for example, disturbed calcium homeostasis, oxidative stress, breakdown of the mitochondrial membrane potential, and release of mitochondrial factors that initiate downstream apoptotic cell death programs. ${ }^{2}$ In particular, mitochondrial membrane permeabilization is considered as a critical step for the release of pro-apoptotic proteins such as cytochrome $c$, Smac/Diablo (second mitochondria-derived activator of caspase/direct IAP binding protein with low $\mathrm{p} /$ ), HtrA2/Omi, apoptosis-inducing factor (AIF), or endonuclease $\mathrm{G}$, which trigger caspase-dependent or caspase-independent mechanisms of DNA degradation and cell death. ${ }^{3,4}$
An increasing number of recent studies provide evidence that AIF is a major factor for an alternative post-mitochondrial cell death pathway, for example, following hypoxia, ${ }^{5,6}$ ischemia, ${ }^{7,8}$ or excitotoxic lesions. ${ }^{9,10}$ AIF is a $63 \mathrm{kDa}$ flavoprotein located at the inner mitochondrial membrane that is released early after oxygen-glucose deprivation in vitro or cerebral ischemia in vivo. ${ }^{7}$ Using harlequin $(\mathrm{Hq})$ mutant mice expressing low AIF levels and small interfering RNA (siRNA) approaches, we recently demonstrated a causal role of AIF in neuronal cell death in models of ischemic stroke in adult rodents $^{8}$ and neonatal hypoxia. ${ }^{6}$ In these studies, we found that nuclear translocation of AIF correlated well with DNA damage and progression of infarct development. Furthermore, AIF downregulation in mutant mice and by AIF siRNA significantly reduced neuronal damage in models of ischemic stroke in vivo and in vitro, respectively.

\footnotetext{
${ }^{1}$ Pharmaceutical Biology-Biotechnology, Ludwig-Maximilians-University, Munich, Germany; ${ }^{2}$ Pharmaceutical Biology, Department of Pharmacy, Ludwig-MaximiliansUniversity, Munich, Germany; ${ }^{3}$ Adolf-Butenandt-Institute for Physiological Chemistry, Ludwig-Maximilians-University, Munich, Germany; ${ }^{4}$ Department of Physics, Ludwig-Maximilians-University, Munich, Germany; ${ }^{5}$ Clinical Pharmacy - Pharmacology and Toxicology, Faculty of Pharmacy, Philipps-University of Marburg, Germany; ${ }^{6}$ Department of Medicine, Division of Medical Oncology, University of Texas Health Science Center, San Antonio, TX, USA; ${ }^{7}$ The Burnham Institute, La Jolla, CA, USA; ${ }^{8}$ Institute for Surgical Research, University of Munich Medical Center-Großhadern, Munich, Germany and ${ }^{9}$ Department of Neurosurgery, University of Munich Medical Center-Großhadern, Munich, Germany

${ }^{*}$ Corresponding authors: C Culmsee, Pharmaceutical Biology-Biotechnology, Department of Pharmacy, Ludwig-Maximilians-University, Butenandtstraße 5-13D, 81377 Munich, Germany. Tel: + 49 (0)89 2180 77456; Fax: + 49 (0)89 2180 77791; E-mail: carsten.culmsee @ cup.uni-muenchen.de or N Plesnila, Department of Neurosurgery, Institute for Surgical Research, University of Munich Medical Center - Großhadern (VIII, M3.38), Marchioninistrsse 15, 81377 Munich, Germany. Tel: + 4989218076 535; Fax: + 4989218076 532; E-mail: Plesnila@med.uni-muenchen.de

${ }^{10}$ Current address: Department of Neurodegeneration, Royal College of Surgeons in Ireland (RCSI), 2 St. Steven's Green, Dublin 2, Ireland

${ }^{11}$ Current address: Clinical Pharmacy - Pharmacology and Toxicology, Faculty of Pharmacy, Philipps-University of Marburg, Karl-von-Frisch Strasse 1, 35043 Marburg, Germany

Keywords: HT-22 cells; glutamate; apoptosis; mitochondrial membrane potential; caspase-independent cell death

Abbreviations: AIF, apoptosis-inducing factor; ANOVA, analysis of variance; CCCP, carbonyl cyanide $m$-chlorophenylhydrazone; FACS, fluorescent-activated cell sorting; FITC, fluorescein isothiocyanate; GFP, green fluorescent protein; Hq, harlequin; JC-1, 5,5',6,6'-tetrachloro-1,1 $1^{\prime}, 3,3^{\prime}$-tetraethylbenzimidazolyl-carbocyanine iodide; MTT, 3-(4,5-dimethylthiazol-2-yl)-2,5-diphenyltetrazolium bromide; PARP, poly-(ADP-ribose)-polymerase-1; RT-PCR, reverse transcription-PCR; siRNA, small interfering RNA; Smac/Diablo, second mitochondria-derived activator of caspase/direct IAP binding protein with low pl; STS, staurosporine; tBid, truncated Bid Received 30.11.07; revised 14.4.08; accepted 05.5.08; Edited by G Kroemer; published online 06.6.08
} 
Despite this prominent role of AIF in neuronal cell death signaling, upstream mechanisms of AIF release from mitochondria are poorly defined. Although previous studies from our and other laboratories had suggested a particular role of poly-(ADP-ribose)-polymerase-1 (PARP) ${ }^{8,11,12}$ and calpain$1^{13}$ in the release of AIF from mitochondria, the immediate upstream mechanisms of mitochondrial AIF release and, in particular, the role of pro-apoptotic bcl-2 family members are not well understood. Our previous studies demonstrated a significant involvement of Bid (BH3-interacting domain death agonist), a pro-apoptotic bcl-2 family protein, in ischemic brain injury $^{14}$ and a pronounced protective effect of pharmacological Bid inhibitors in models of neuronal cell death in vitro. Very similar neuroprotective effects were observed in mutant $\mathrm{Hq}$ mice or by AIF siRNA, ${ }^{8}$ suggesting a link between proapoptotic Bid activities and AIF release from mitochondria. In the present study, we therefore investigated the potential role of Bid in mitochondrial release of AIF during excitotoxic neuronal cell death in more detail.

\section{Results}

Bid gene silencing and Bid inhibition attenuate glutamate neurotoxicity. Significant $(60-80 \%)$ glutamateinduced cell death occurs in immortalized mouse hippocampal neurons (HT-22) in a concentration-dependent manner (Figure 1a). Bid translocated to mitochondria within $5 \mathrm{~h}$ after the onset of glutamate challenge (Figure 1b). Bid siRNA specifically reduced Bid expression by $>80 \%$ (Figure 1c) and significantly attenuated glutamate-induced cell death (Figure 1d). In addition to the siRNA approach, the specific Bid inhibitor BI-6C9 (Sigma, Taufkirchen, Germany) ${ }^{15,16}$ was applied to confirm the essential role of Bid in glutamate-induced neuronal death. HT-22 neurons exposed to glutamate for $17 \mathrm{~h}$ show typical morphology of dying cells: the neuronal cells appear shrunken and rounded and detached from the culture dish (Figure 2a). HT-22 cells pretreated with the Bid inhibitor $\mathrm{Bl}-6 \mathrm{C} 9$ preserved their normal spindle-shaped morphology and were completely rescued from glutamate-induced cell death (Figure 2a). Fluorescent-activated cell sorting (FACS) analysis of fluorescein isothiocyanate (FITC)-annexin-V-stained HT-22 neurons confirmed the pronounced protective effect of the Bid inhibitor against glutamate-induced cell death (Figure 2b). Bid inhibition-related neuroprotection was associated with a lack of Bid translocation to the mitochondria as shown in experiments using the pDsRed2Bid vector and Mito-green fluorescent protein (GFP) cotransfections (Figure 2c) or Mitotracker Green staining (not shown), indicating that Bid translocation is essential for neuronal cell death. In addition, the Bid inhibitor prevented the perinuclear accumulation of mitochondria in glutamatetreated cells (Figure 2c).

Concomitant detection of propidium iodide $(\mathrm{PI})$ revealed that less than $9.5 \pm 1.7 \%$ of the glutamate-treated cells were PI positive versus $5.4 \pm 0.6 \%$ in the controls, suggesting that most HT-22 cells exposed apoptotic and not necrotic features after glutamate exposure (data not shown). Strikingly, morphological analysis and 3-(4,5-dimethylthiazol-2-yl)-2,5- diphenyltetrazolium bromide (MTT) assay revealed that the Bid inhibitor $\mathrm{BI}-6 \mathrm{C} 9$ significantly rescued $\mathrm{HT}-22$ neurons even when applied up to $8 \mathrm{~h}$ after glutamate exposure, suggesting that Bid-mediated cell death depends on sustained Bid activation with a remarkable time window (Supplementary Figure 1).

The specificity of $\mathrm{BI}-6 \mathrm{C} 9$ in the presently used culture system was confirmed in $\mathrm{HT}-22$ neurons transfected with a truncated Bid (tBid) expression vector. Expression of tBid in HT-22 neurons reduced cell viability by approximately $40 \%$, whereas cells pretreated with the Bid inhibitor were significantly protected from tBid-induced cell death (Supplementary Figure 2). It is important to note that the percentage of cell death detected in tBid-transfected HT-22 neurons corresponds well with the transfection efficiency achieved with the current protocol for DNA vector transfection (45 $\pm 3-51 \pm 1 \%$ ), indicating that pharmacological inhibition of tBid translocation to the mitochondria rescued all transfected neurons.

Glutamate induces Bid-dependent mitochondrial depolarization. Glutamate treatment caused a significant loss of $5,5^{\prime}, 6,6^{\prime}$-tetrachloro-1, $1^{\prime}, 3,3^{\prime}$-tetraethylbenzimidazolylcarbocyanine iodide (JC-1) red fluorescence, that is, loss of mitochondrial membrane potential after glutamate treatment within 6-12 h (Figure 3). In parallel experiments, carbonyl cyanide $m$-chlorophenylhydrazone (CCCP) was used as a positive control to induce mitochondrial membrane depolarization (Figure 3c). The Bid inhibitor Bl-6C9 significantly prevented glutamate-induced breakdown of the mitochondrial membrane potential, suggesting that the Bid inhibitor significantly prevented Bid translocation to the mitochondria and consequently prevented glutamateinduced breakdown of the mitochondrial membrane potential in HT-22 neurons (Figures $2 \mathrm{c}$ and 3 ). In addition, protection of the mitochondrial membrane potential was confirmed by Bid siRNA, which significantly attenuated the loss of JC-1 red fluorescence compared with nonfunctional Mut siRNA after the glutamate challenge (Figure $3 d$ ).

Caspase activation is not required for glutamate neurotoxicity. After Bid activation, subsequent mitochondrial membrane permeabilization may trigger both caspasedependent and caspase-independent execution of cell death through the release of cytochrome $c$ and apoptosome formation or AIF, respectively. ${ }^{2}$ Measurements of caspase-3 activity indeed revealed moderate caspase- 3 activation after exposure of HT-22 neurons to glutamate and this activation was completely blocked by Bid inhibition (Figure 4a). Similar inhibition of caspase-3 activity was also achieved with the membrane-permeable general caspase inhibitor Z-VAD-FMK (Figure 4b); however, this treatment did not affect glutamateinduced cell death (Figure 4c). These data therefore suggest that caspase- 3 activation occurs after glutamate exposure in HT-22 neurons but is not required for execution of the cell death program. It is interesting to note that respective inhibitors of caspase-8 (IETD-fmk, 10-50 $\mu \mathrm{M}$; Supplementary Figure 3), caspase-2 (Z-VDVAD, 5-50 $\mu \mathrm{M})$, calpain (calpastatin, $0.5-5 \mu \mathrm{M}$ after preincubation with equimolar amounts of activated penetratin-1), or cathepsins (E-64-d, 10-50 $\mu \mathrm{M}$ ) also did not prevent glutamate-induced 

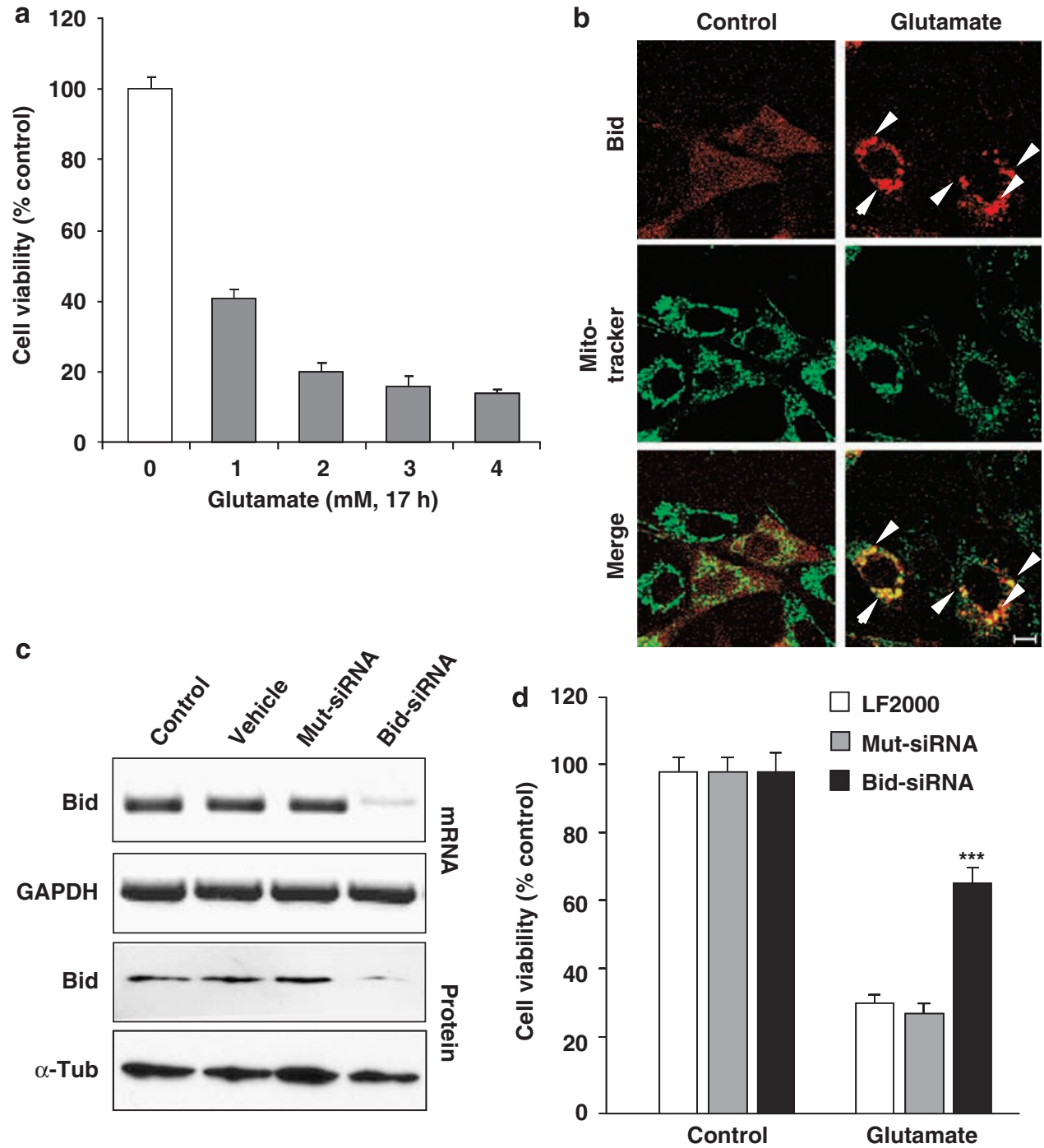

Figure 1 Bid knockdown rescued HT-22 neurons from glutamate-induced apoptosis. (a) Glutamate reduces the viability of HT-22 neurons in a concentration-dependent manner as evaluated by the MTT assay $17 \mathrm{~h}$ after the onset of treatment. (b) Fluorescence photomicrographs of HT-22 neurons expressing a Bid-DsRed fusion protein show colocalization of MitoTracker Green and DsRed signal in glutamate-damaged $(5 \mathrm{mM}, 5 \mathrm{~h})$ cells. Similar results were obtained in cells exposed to $3 \mathrm{mM}$ glutamate. Note that the homogeneous distribution of Bid in control cells significantly changes after glutamate damage where Bid accumulates at mitochondria (yellow in merged panels). (c) RT-PCR analysis of Bid mRNA (upper panels) and western blot analysis of Bid protein (lower panels) in HT-22 cells pretreated with $20 \mathrm{nM}$ Bid siRNA for $48 \mathrm{~h}$. RT-PCR with primers specific for glyceraldehyde-3-phosphate dehydrogenase (GAPDH) and anti- $\beta$-actin antibodies used as controls for respective analyses is shown. (d) Bid siRNA significantly attenuated glutamate-induced cell death as determined by MTT assay. ${ }^{\star \star \star} P<0.001$ compared with glutamate-exposed $(3 \mathrm{mM}) \mathrm{HT}$-22 cells pretreated with nonfunctional Mut siRNA or vehicle (Lipofectamine 2000) (analysis of variance (ANOVA), Scheffé's)

cell death in HT-22 neurons. In addition, caspase-8 activity was not altered after glutamate challenge, suggesting that this prominent pathway of Bid activation was not involved in the present model system (not shown).

Bid-induced neurotoxicity is mediated by AIF. The current failure of caspase inhibitors to prevent HT-22 cell death further supports our recent data demonstrating a major role for AIF in glutamate-induced neuronal cell death. ${ }^{8,16}$ To evaluate the specific role of Bid in mitochondrial AIF release and subsequent nuclear translocation, we exposed HT-22 neurons expressing AIF-GFP fusion protein to glutamate and analyzed AIF translocation to the nucleus in the presence or absence of the Bid inhibitor. Confocal microscopy time-lapse recordings taken every 5 min over a period of $18 \mathrm{~h}$ after glutamate exposure revealed that mitochondria containing AIF-GFP fusion protein accumulated around the nucleus within 8-10 h after the onset of apoptotic challenge. Accumulation of mitochondria around the nucleus was followed by a rapid release of AIF into the nucleus within less than $15 \mathrm{~min}$ (Supplementary Movie). This very close temporal relationship between nuclear AIF translocation and cell death points to a crucial role of AIF in the cell death process and suggests that AIF is one of the final steps in caspase-independent cell death signaling. The Bid inhibitor BI-6C9 blocked glutamate-induced translocation of endogenous and GFP-linked AIF as detected by confocal microscopy (Figure 5a and Supplementary Figure 4) and 
a
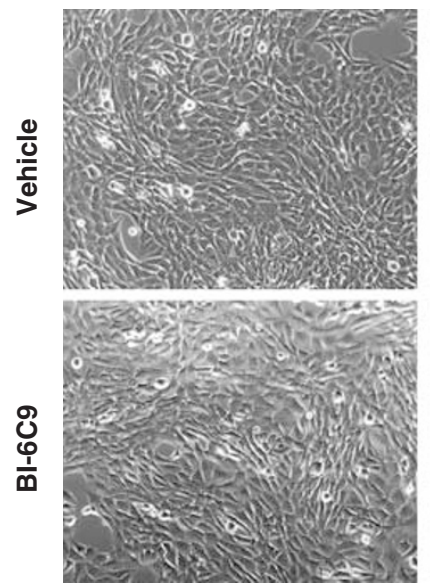

C
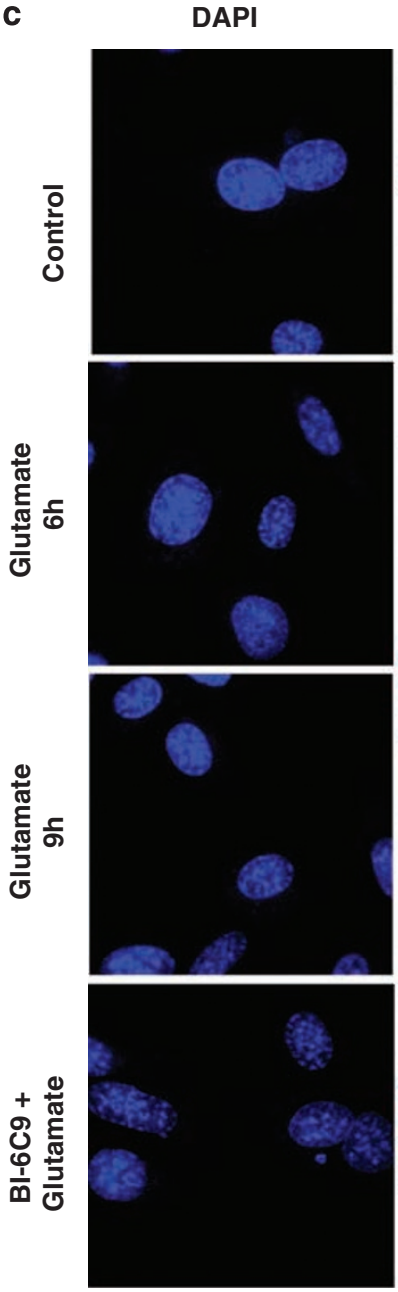

\section{Glutamate}
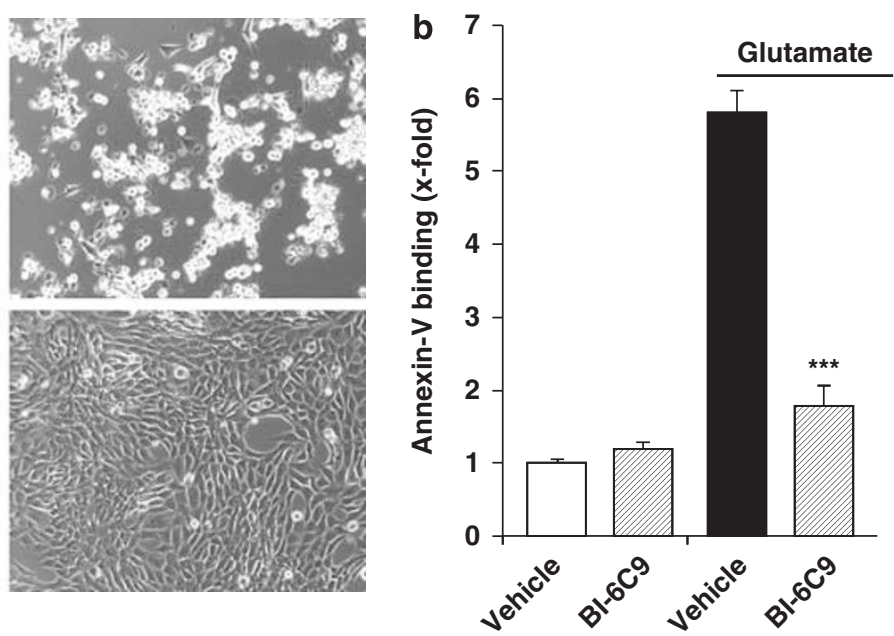

BID
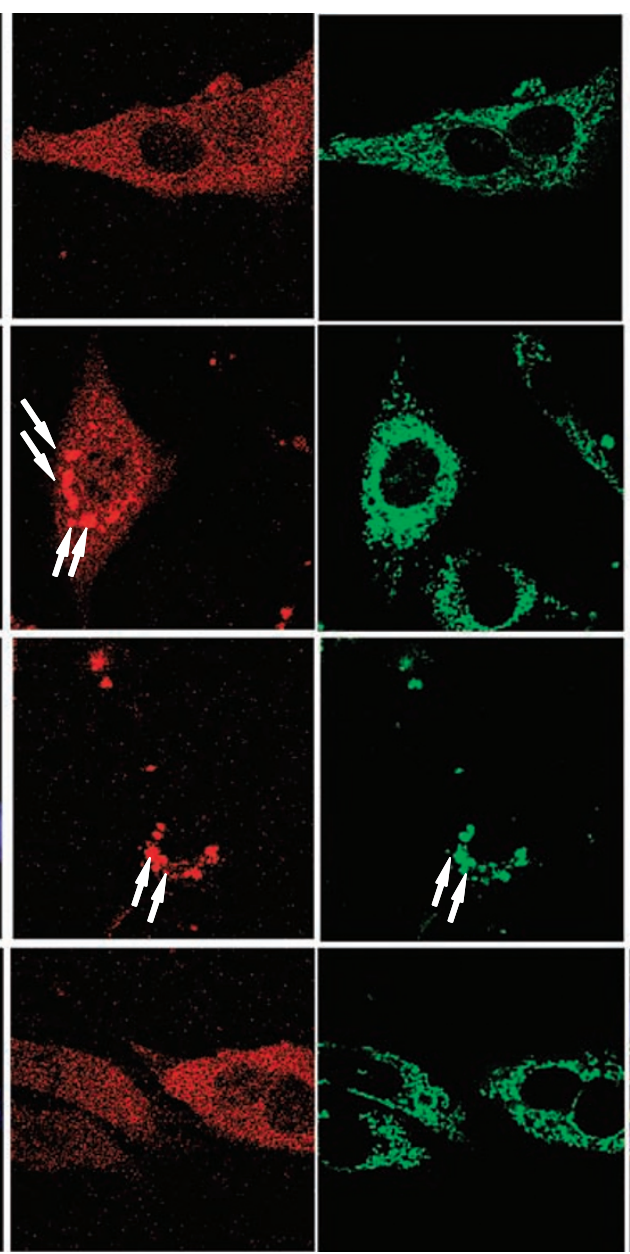

Merge
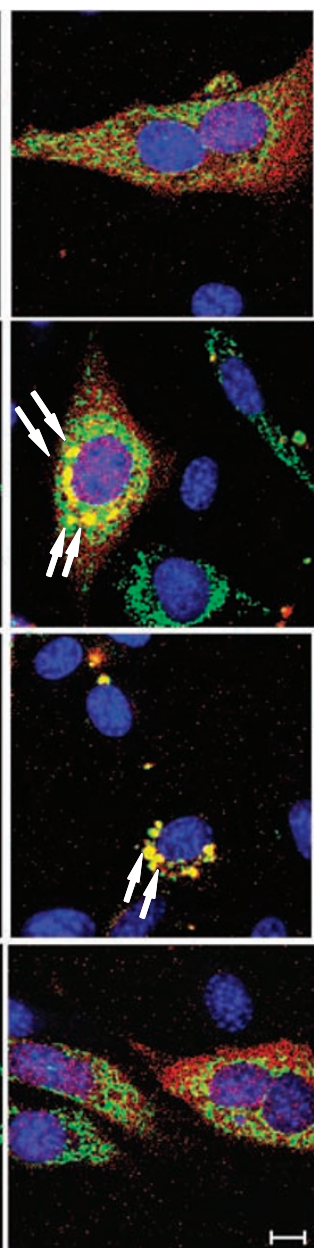

Figure 2 The Bid inhibitor BI-6C9 protects HT-22 cells against glutamate-induced apoptosis. (a) Photomicrographs ( $\times 10$ objective) show morphological evidence for severe damage of HT-22 cells $17 \mathrm{~h}$ after glutamate $(3 \mathrm{mM})$ exposure. Glutamate-treated cells lose their spindle-like morphology, shrink, and detach from the culture well bottom; in contrast, cells pretreated with the Bid inhibitor BI-6C9 $(10 \mu \mathrm{M})$ are fully protected against glutamate-induced death and are not different from the controls. (b) FACS analysis of HT-22 cells after FITC-annexin-V labeling to detect apoptotic cells. Exposure to glutamate $(3 \mathrm{mM}, 17 \mathrm{~h})$ resulted in enhanced annexin-V binding of apoptotic $\mathrm{HT}$-22 cells compared with controls. BI-6C9 $\left(10 \mu \mathrm{M}, 1 \mathrm{~h}\right.$ before damage) significantly reduced glutamate-induced apoptosis. ${ }^{* \star} P<0.001$ compared with glutamate-treated cells (Student's t-test). (c) The Bid inhibitor prevents mitochondrial translocation of Bid after glutamate exposure. Fluorescence photomicrographs of HT-22 neurons expressing a Bid-DsRed fusion protein and Mito-GFP show colocalization of mitochondrial staining and DsRed signal in glutamate-damaged $(5 \mathrm{mM}, 6-9 \mathrm{~h})$ cells. The Bid inhibitor BI-6C9 $(10 \mu \mathrm{M})$ prevented the accumulation of Bid at the mitochondria and retained the homogeneous distribution of Bid in the cytosol 
a

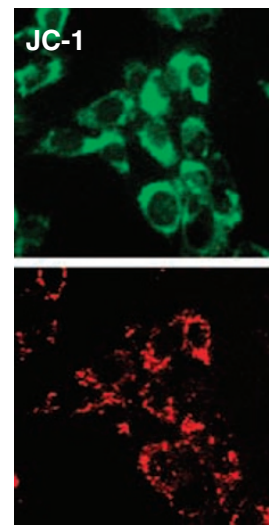

Control
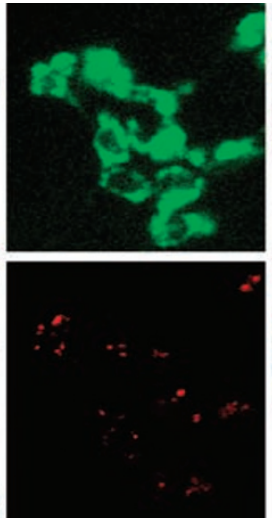

Glutamate

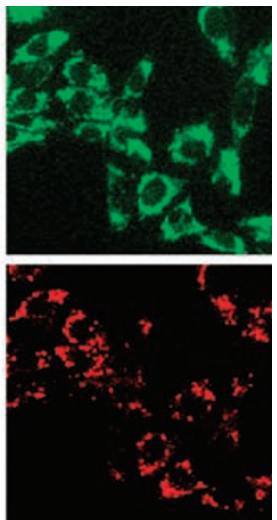

BI-6C9

+ Glutamate

b
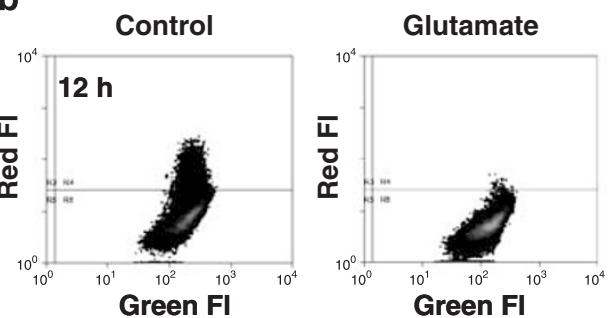

BI-6C9
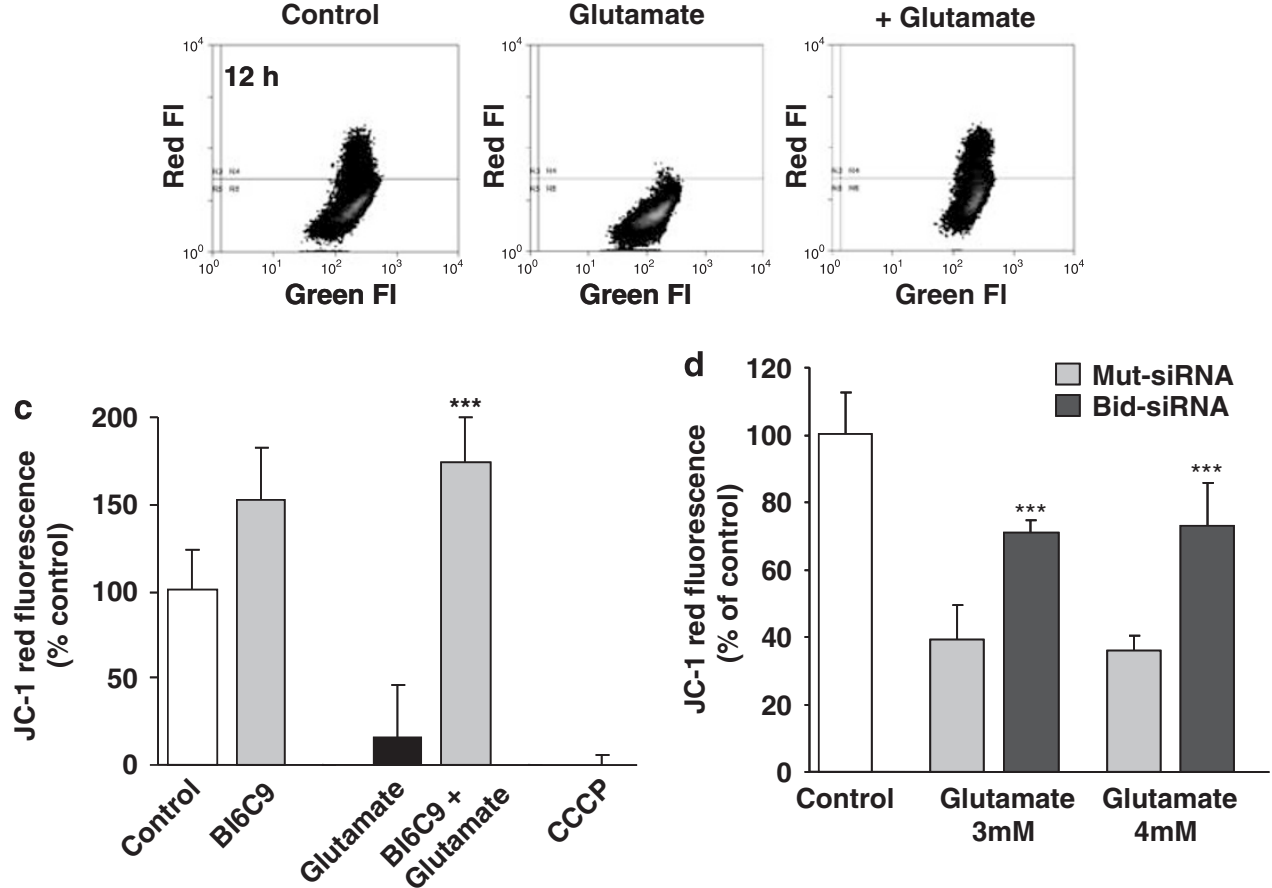

Figure 3 The Bid inhibitor BI-6C9 prevents glutamate-induced mitochondrial depolarization. (a) Mitochondrial membrane potential was analyzed by JC-1 fluorescence: the upper panels show epifluorescence photomicrographs indicating equal cellular uptake of JC-1 by green fluorescence, and the lower panels depict intact mitochondria exposing red fluorescence. Glutamate-treated $(3 \mathrm{mM}, 12 \mathrm{~h}) \mathrm{HT}-22$ cells show significantly reduced red fluorescence compared with controls, whereas BI-6C9 (10 $\mu \mathrm{M})$ prevents the breakdown of mitochondrial membrane potential as indicated by preservation of the red JC-1 fluorescence. (b, c) FACS analyses of $n=4$ independent experiments per group reveal a decrease of the red JC- 1 fluorescence to $20 \%$ of control levels $12 \mathrm{~h}$ after glutamate treatment ( $3 \mathrm{mM}$ ), which is prevented by BI-6C9. CCCP was used as a positive control to induce a fast breakdown of the mitochondrial membrane potential. ${ }^{* \star *} P<0.001$ compared with controls and BI-6C9-treated cells (ANOVA, Scheffé's). (d) FACS analyses of $n=3$ independent experiments per group show a rescue of the red JC-1 fluorescence by Bid siRNA compared with nonfunctional Mut siRNA-treated HT-22 cells determined $6 \mathrm{~h}$ after the onset of glutamate damage. ${ }^{* \star}{ }^{*} P<0.001$ compared with Mut siRNA-treated cells (ANOVA, Scheffé's)

western blot analysis of nuclear protein extracts (Figure $5 b$ ). Furthermore, the involvement of Bid in endogenous AIF translocation to the nucleus was verified by using Bid siRNA. Western blot analysis confirmed that Bid siRNA prevented AIF translocation to the nucleus after glutamate challenge (Figure 5c).

The potential role of AIF in the execution of cell death downstream of Bid-mediated mitochondrial demise was further addressed by a gene silencing approach. AIF siRNA reduced AIF mRNA and protein levels (Figure 6a) and significantly attenuated glutamate-induced cell death in HT-22 cells (Figure 6b). Most intriguingly, we found that AIF siRNA prevented tBid-induced cell death in HT-22 neurons (Figure 6c), demonstrating that tBid-induced neurotoxicity is mediated by AIF. Taken together, these findings demonstrate that Bid is responsible for mitochondrial AIF release and induces caspase-independent execution of neuronal cell death. 

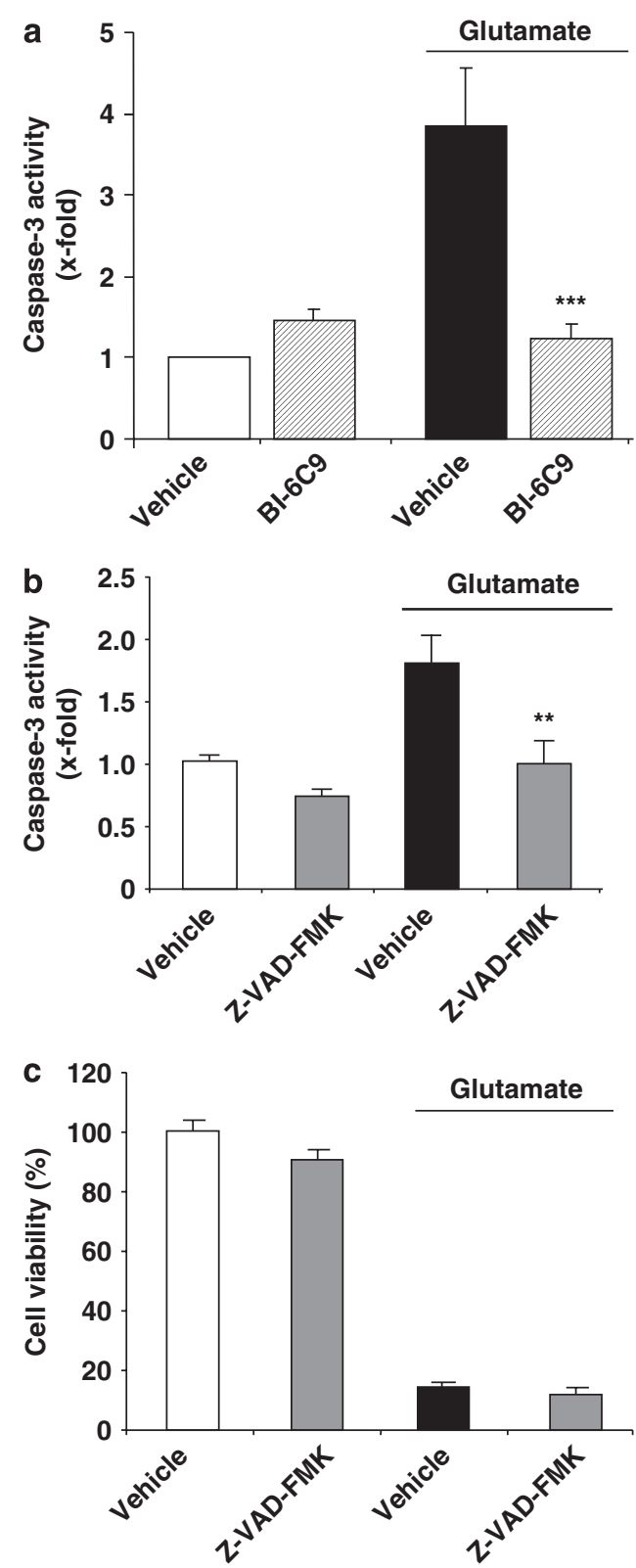

Figure 4 Caspase activation is not required in glutamate neurotoxicity. (a) Caspase-3 activity assay showed an increased caspase-3 activity after glutamate treatment $(2 \mathrm{mM}, 17 \mathrm{~h})$ that was prevented by Bl-6C9 $(10 \mu \mathrm{M})$. (b) Caspase-3 activation was prevented by the pan-caspase inhibitor Z-VAD-FMK $(50 \mu \mathrm{M})$ applied $1 \mathrm{~h}$ before glutamate exposure. (c) MTT assay revealed that Z-VAD-FMK $(50 \mu \mathrm{M})$ could not protect $\mathrm{HT}-22$ neurons from glutamate-induced cell death. ${ }^{* *} P<0.01$ and ${ }^{\star \star \star} P<0.001$ compared to vehicle-treated cells exposed to glutamate (ANOVA, Scheffé's test)

\section{Discussion}

The present study demonstrates a key role for the proapoptotic bcl-2 family protein Bid in mitochondrial membrane permeabilization and the subsequent nuclear translocation of AIF in HT-22 neurons exposed to lethal glutamate concentrations. The glutamate challenge induced translocation of Bid to mitochondria, followed by mitochondrial membrane depolarization and AIF release to the nucleus rapidly followed by nuclear pyknosis and disintegration of the cell membrane, that is, cell death. The pharmacological Bid inhibitor BI-6C9 and siRNA-mediated gene silencing both significantly prevented mitochondrial Bid translocation, migration of AIF to the nucleus, and, hence, glutamate-induced cell death.

These findings are corroborated by findings in primary neurons, as mitochondrial cell death pathways are key mechanisms in various models of neuronal cell death, including related models of glutamate-mediated excitotoxicity. In particular, recent data established a pivotal role for Bid upstream of mitochondrial demise in neuronal cell death. ${ }^{17}$ In addition to pro-apoptotic Bid activation by caspase-8mediated cleavage to tBid and subsequent translocation from the cytosol to mitochondria in death receptor-mediated cell death, more recent data suggest a role for full-length Bid in caspase-independent apoptosis. ${ }^{18-20}$ In these studies in primary cultured neurons, translocation of full-length Bid to mitochondria following exposure to glutamate coincided with a collapse of the mitochondrial membrane potential. ${ }^{18-20} \mathrm{How}$ full-length Bid is activated to mediate mitochondrial demise is currently unknown. Beyond potential interactions with Bax (Bcl-2-associated $\mathrm{X}$ protein) or Bak (Bcl-2 antagonist killer) to form mitochondrial outer membrane pores that allow the unspecific release of a whole series of mitochondrial proteins, for example cytochrome $c$, Smac/Diablo, or AIF, Bid may affect mitochondrial morphology by increasing mitochondrial fission or alterations in mitochondrial cristae organization. ${ }^{21,22}$ In addition, PARP, another pro-apoptotic factor that has been linked to mitochondrial demise and AIF translocation to the nucleus in neuronal cell death, ${ }^{8,11,12}$ may complement the presently investigated Bid-dependent mechanisms as PARP inhibition also prevents AIF-dependent neuronal death. ${ }^{8,11}$ To the best of our knowledge, however, an interaction between Bid and PARP in mitochondrial cell death pathways has not been elucidated yet. These and other so far not defined activities of mitochondrial Bid may explain the apparent delay between Bid accumulation in mitochondria and the observed mitochondrial morphological changes, perinuclear accumulation, and AIF release after the glutamate challenge in HT-22 cells.

Here, we demonstrate that pharmacological Bid inhibition prevents the translocation of Bid to mitochondria and the proapoptotic activity of tBid as well as the subsequent loss of mitochondrial membrane potential and AIF-induced nuclear fragmentation. In line with earlier studies in HeLa cells and isolated mitochondria ${ }^{15,16}$ the specificity of the Bid inhibitor was confirmed in tBid-transfected HT-22 cells (Supplementary Figure 2). The causal role of Bid in the current paradigm was further confirmed in parallel experiments using Bid siRNA, which also prevented AIF translocation and glutamate-induced cell death, findings corroborated by pharmacological inhibition of Bid (Supplementary Figure 4). In addition, our parallel experiments in primary cultured neurons demonstrated pronounced neuroprotective effects of different Bid inhibitors in models of glutamate-induced apoptosis ${ }^{16}$ or oxygen-glucose deprivation. ${ }^{8}$ In both models of neuronal cell death, activation of glutamate receptors mediates a rapid increase in intracellular calcium levels and an excitotoxic death program that involves the formation of reactive oxygen species, permeabilization of the mitochondrial membrane, 
a

\section{Control}
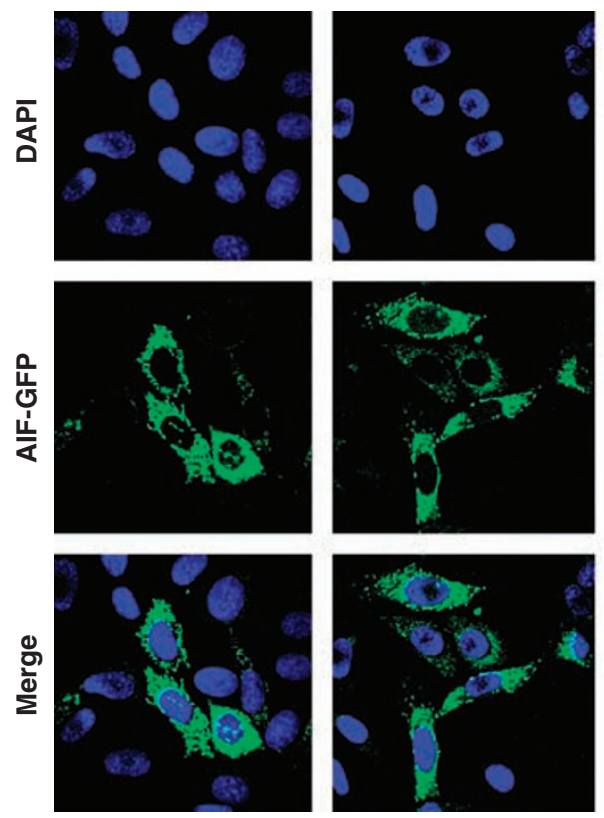

b

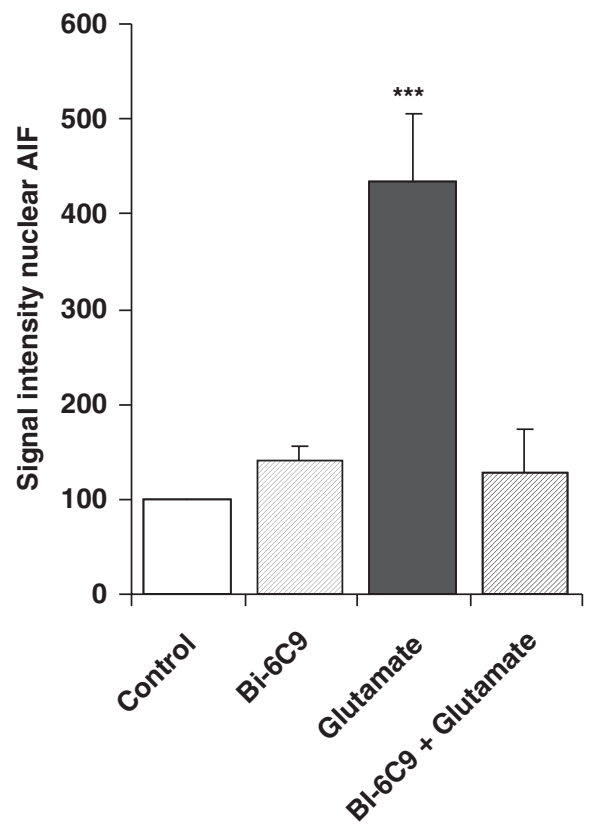

BI-6C9
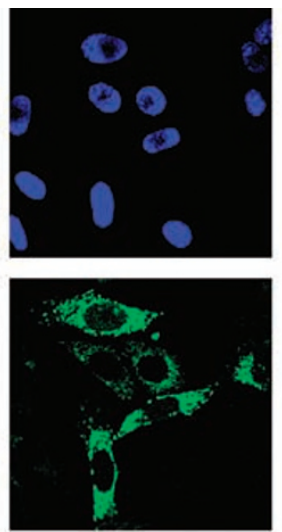
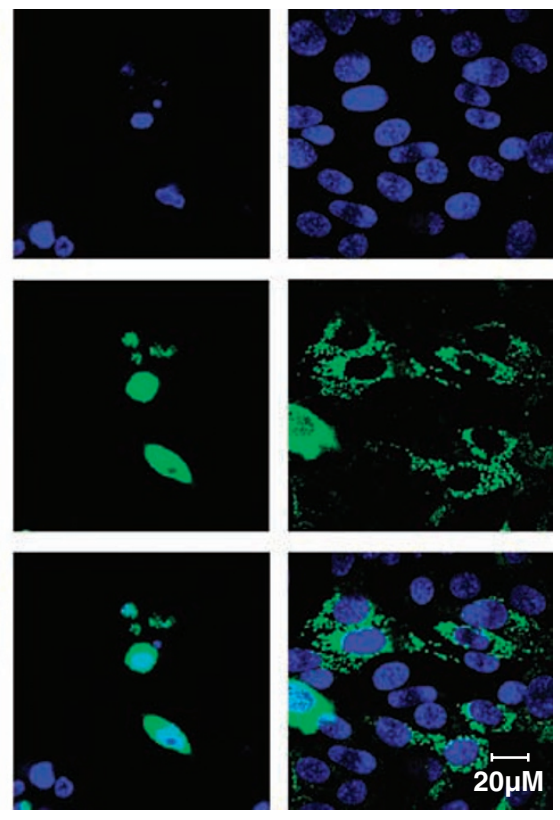

c

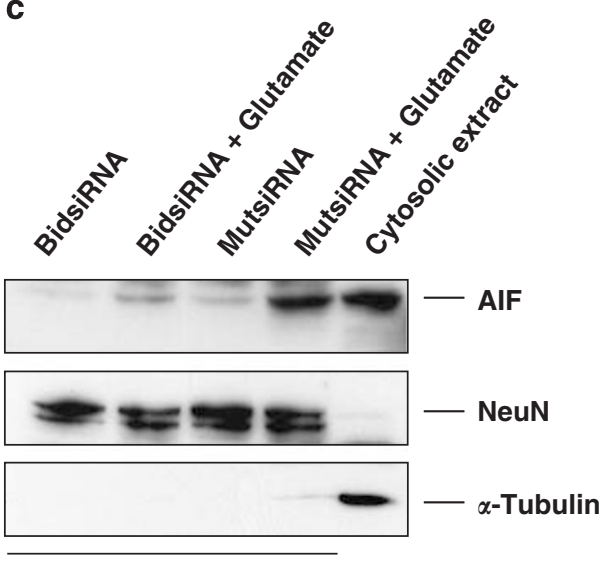

Nucleus
BIBI-6C9 +

Glutamate
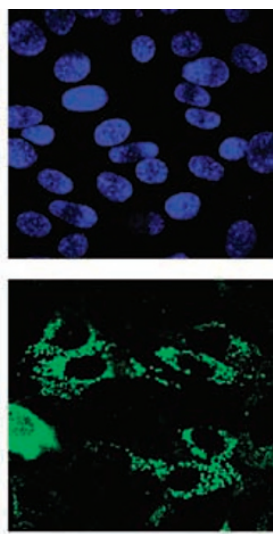

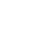



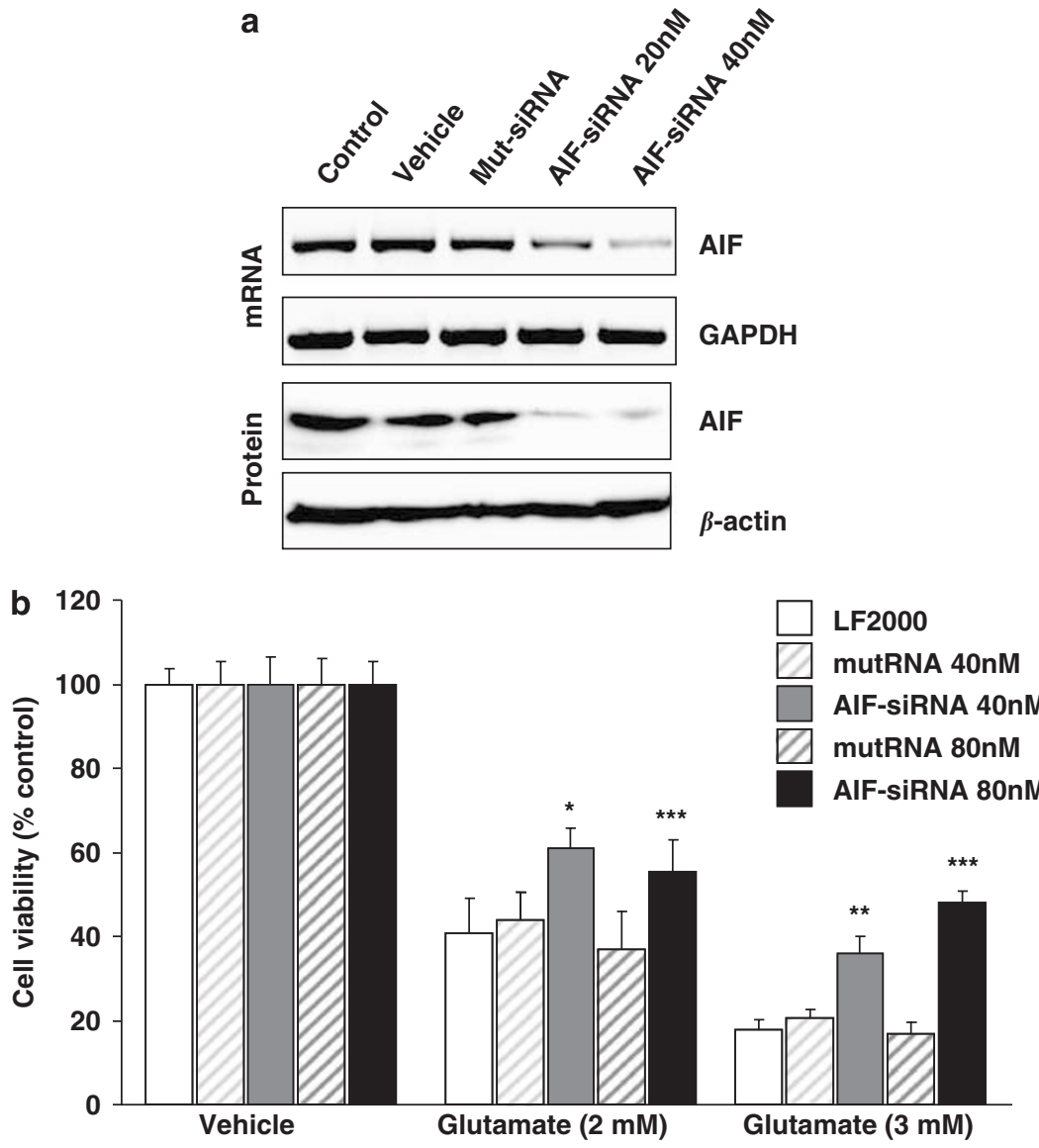

C

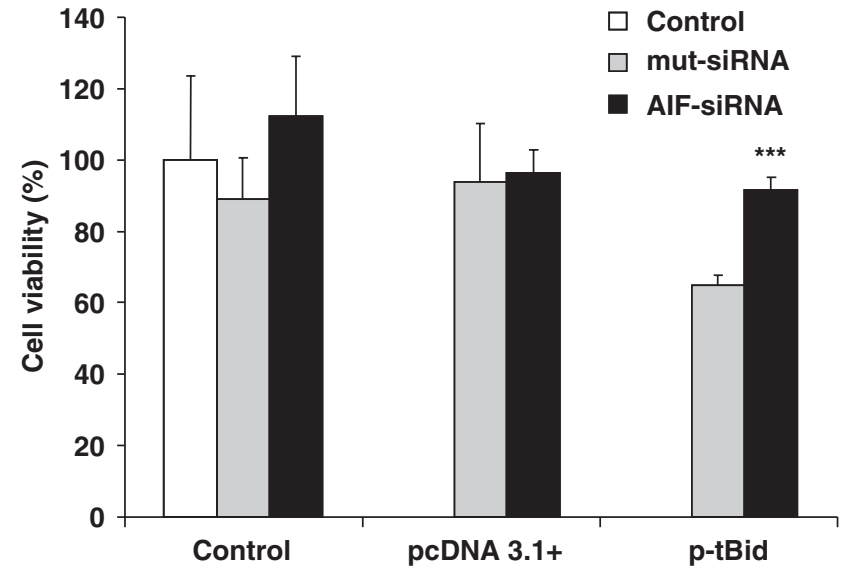

Figure 6 AIF siRNA attenuates glutamate- and tBid-induced toxicity in HT-22 neurons. (a) AIF siRNA ( $20-40 \mathrm{nM}$ ) was applied to HT-22 cells $48 \mathrm{~h}$ before analysis of mRNA levels by RT-PCR (upper panels) or protein analysis by western blot (lower panels). Nonfunctional Mut siRNA or Lipofectamine 2000 (vehicle) was applied in control experiments, and GAPDH or $\beta$-actin was analyzed as a respective control for RT-PCR or western blot. (b) AIF siRNA (40-80 nM) was applied to HT-22 cells $48 \mathrm{~h}$ before glutamate $(2-3 \mathrm{mM})$. Cell viability was assessed by the MTT assay $18 \mathrm{~h}$ later. Mean values and S.D. of $n=6$ experiments per group are shown; ${ }^{\star} P<0.05$, ${ }^{\star \star} P<0.01$, and ${ }_{* \star \star} P<0.001$ compared with respective mut siRNA treatments (ANOVA, Scheffé's). (c) HT-22 cells were transfected with AIF siRNA (50 nM) $24 \mathrm{~h}$ before transfection with a tBid-expressing plasmid $(1 \mu \mathrm{g})$. Analysis of cell viability by the MTT assay $24 \mathrm{~h}$ later revealed protection of HT-22 neurons against tBid-induced cell death by AIF siRNA. ${ }^{* * \star} P<0.001$ compared with $p$-tBid-transfected cells (Student's $t$-test). Metabolic activity of HT-22 was neither affected by control plasmid $3.1+$ nor by nonfunctional mut SiRNA

suggest that Bid-induced AIF-mediated cell death signaling is not confined to glutamate toxicity alone but also present in other cell death paradigms.

The relevance of the current data on the key role for Bid in neuronal cell death in vitro is further underlined by recent data obtained in in vivo models of cerebral ischemia ${ }^{14,23}$ and brain trauma. ${ }^{24}$ In both models of acute brain injury, Bid cleavage has been detected after the respective insults, and knockout of the Bid gene resulted in significant cerebroprotective effects compared with wild-type animals. Therefore, the 
understanding of Bid-dependent cell death mechanisms is of utmost importance, and the presently used Bid inhibitors may emerge as promising lead structures for neuroprotective drugs in the treatment of neurodegenerative diseases.

The second important aspect of the present study addresses the role of AIF in mediating caspase-independent cell death downstream of Bid activation. It has been well established that mitochondrial membrane permeabilization results in the release of pro-apoptotic factors such as cytochrome $c$, Smac/Diablo, Omi/HtrA2, and AIF, which may execute cell death through caspase-dependent or caspase-independent mechanisms. For example, formation of the apoptosome by cytochrome $c$, Apaf-1, and procaspase9 and downstream catalytic activation of executor caspases (caspase-3, -6, or -7) are widely established mechanisms of caspase-dependent cell death execution downstream of mitochondrial damage in many cells, including neurons. Here, we detected caspase-3 activation downstream of Bid, suggesting that this pathway may also play a role in neuronal cell death in the present model. Caspase-3 inhibition alone, however, did not prevent glutamate-induced cell death (Figure 4). Because other signs of executor caspase activation, for example, cleavage of $\alpha$-fodrin or lamin, were also not detected (data not shown), our data strongly suggest a major role for caspase-independent cell death downstream of mitochondrial membrane permeabilization. Using an AIFGFP construct, we found mitochondrial release of AIF and translocation to the nucleus, which occurred around 8-10 h after the onset of glutamate exposure. Time-lapse video recordings revealed that the time point of massive AIF translocation to the nucleus may vary from cell to cell around 8-12 $\mathrm{h}$ after the insult, but once started, the AIF translocation occurs within $15 \mathrm{~min}$ and is followed by rapid nuclear condensation and cellular fragmentation (Supplementary Movie). This is, to our knowledge, the first time that the kinetics of AIF-mediated cell death has been recorded in living cells. After hours of increasing Bid translocation to the mitochondria and perinuclear accumulation of Bid-loaded mitochondria, the final execution of cell death by the released AIF takes only a few minutes. The markedly fast kinetics of AIF translocation into the nucleus once released from the mitochondria further exposes the unique role of AIF downstream of mitochondrial demise to mediate cell death independent of other established execution mechanisms of intrinsic cell death pathways, such as apoptosome formation and activation of caspase-3. Furthermore, AIF siRNA significantly attenuated glutamate-induced neurotoxicity in HT-22 cells (Figure $6 a$ and $b$ ) and in primary neurons; ${ }^{16}$ most intriguingly, AIF siRNA also prevented tBid-induced cell death in HT-22 neurons (Figure 6c), clearly demonstrating that Bid neurotoxicity is predominantly mediated by mitochondrial AIF release and hence caspase-independent cell death pathways.

The present findings are in accordance with recent data where we and others demonstrated a key role for AIF in delayed neuronal cell death after excitotoxic or hypoxia/ ischemia insults in vitro and in vivo. ${ }^{6,8,9}$ Furthermore, these results propose that the release of pro-apoptotic factors is a coordinated process where the release of a particular apoptotic factor and its role in the execution of apoptosis also depends on the stress challenge and the pathway to mitochondrial damage. The present model of glutamate toxicity in HT-22 neurons features Bid-mediated mitochondrial membrane permeabilization and release of AIF, whereas activation of Bid and AIF release were not required for staurosporine (STS)-induced apoptosis (Supplementary Figure 5), which is consistent with previous reports. ${ }^{25,26}$ Similar differences between mitochondrial proteins regarding their release and involvement in neuronal death were detected after cerebral ischemia in vivo, where early AIF release from the mitochondria correlated well with the progression of DNA damage and nuclear pyknosis in neurons whereas cytochrome $c$ release and activation of caspases were detected as a later event, less frequently and in different cells than the AIF translocation. ${ }^{7}$

In summary, our data link enhanced Bid activation to mitochondrial AIF release and caspase-independent execution of neuronal cell death, which are both key features in delayed neuronal cell death after excitotoxic or ischemic insults in models of stroke, epilepsy, and brain trauma. Therefore, Bid emerges as a promising target for therapeutic approaches that prevent mitochondrial damage after neuronal injury.

\section{Materials and Methods}

Cell culture and induction of neuronal cell death. HT-22 cells were cultured in Dulbecco's modified Eagle's medium (Invitrogen, Karlsruhe, Germany) supplemented with $10 \%$ heat-inactivated fetal calf serum, $100 \mathrm{U} / \mathrm{ml}$ penicillin, $100 \mu \mathrm{g} / \mathrm{ml}$ streptomycin, and $2 \mathrm{mM}$ glutamine. Glutamate $(1-4 \mathrm{mM})$ or STS $(300 \mathrm{nM})$ was added to the serum-containing medium, and cell viability was evaluated $17-20 \mathrm{~h}$ later.

Plasmids and gene transfer. Plasmid pCDNA $3.1+$ was obtained from Invitrogen. The mouse AIF-GFP fusion protein vector (mAIF_pd2EGFP-N1) was derived from a pd2pEGFP-N1 vector (Clontech, Palo Alto, CA, USA) and an AIFexpressing vector (pcDNA3.1_mAIF, a kind gift of S Susin, CNRS, Paris, France). The tBid vector and control vectors were generated as described previously. ${ }^{27}$ The plasmid pDsRed2-Bid for expression of DsRed fused to the C-terminus of Bid to allow translocation analyses of full-length Bid and tBid was derived from Clontech. Plasmid transfections of $8 \times 10^{4} \mathrm{HT}-22$ cells seeded in 24-well plates were performed in antibiotic-free growth medium using Lipofectamine 2000 (Invitrogen). Controls were treated with $100 \mu \mathrm{l} / \mathrm{ml}$ Optimem only and vehicle controls with 1.5 $\mu \mathrm{l} / \mathrm{ml}$ Lipofectamine 2000

Immunostaining and confocal laser scanning microscopy. For (immuno)fluorescence analyses, HT-22 cells were seeded in collagen A-coated Ibitreat $\mu$-slide eight-well plates (Ibidi, Munich, Germany) at a density of $1 \times 10^{4} \mathrm{cells} /$ well. Mitochondria were stained with MitoTracker Green according to the manufacturer's protocol (Invitrogen) or visualized by co-transfection with a mitochondria-targeted GFP construct as described previously. ${ }^{28}$ End-point pictures were taken after fixation with $4 \%$ paraformaldehyde and 4',6-diamidino-2' phenylindole-dihydrochloride counterstaining of the nuclei between 5 and $17 \mathrm{~h}$ after the onset of treatment. Images were acquired using a confocal laser scanning microscope (LSM 510, Carl Zeiss, Jena, Germany) equipped with a UV, an argon, and a helium/neon laser delivering light at 364,488 , and $543 \mathrm{~nm}$, respectively. For real-time confocal microscopy, the $\mathrm{CO}_{2}$ chamber was adjusted to $37^{\circ} \mathrm{C}, 5 \% \mathrm{CO}_{2}$ and a humidified atmosphere. Images were acquired every $5 \mathrm{~min}$ up to $17 \mathrm{~h}$ after the onset of treatments.

Evaluation cell viability and apoptosis. For morphological analysis of cells, transmission light microscopy of living HT-22 neurons growing as monolayers was performed using an Axiovert 200 microscope (Carl Zeiss) equipped with a Sony DSC-S75 digital camera (Sony Corporation, Tokyo, Japan) and image analysis was performed with the Axiovision 3.1.0.18 software (Carl Zeiss). Quantification of cell viability in HT-22 cells was performed in 96-well plates by MTT reduction at 
$0.5 \mathrm{mg} / \mathrm{ml}$ for $2 \mathrm{~h}^{29}{ }^{29}$ Apoptotic cell death was detected by annexin-V/propidium iodide staining (Sigma-Aldrich, Taufkirchen, Germany) and subsequent flow cytometry analysis using a CyanTM MLE flow cytometer (DakoCytomation, Copenhagen, Denmark). Cells were appropriately gated by forward versus side scatter and pulse width, and $1 \times 10^{4}$ gated events per sample were collected. Surviving cells did not show any staining whereas annexin- $V$ staining indicated apoptosis and cells positive for both annexin $\mathrm{V}$ and propidium iodide were regarded necrotic.

Analysis of mitochondrial membrane potential. Mitochondrial membrane potential of HT-22 neurons was determined by JC-1 reduction according to the manufacturer's protocol (Mitoprobe, Invitrogen) and analyzed by subsequent flow cytometry or epifluorescence microscopy. Additional controls were treated with $\operatorname{CCCP~}(50 \mu \mathrm{M}) 5$ min before staining to induce mitochondrial membrane depolarization

Gene silencing. AIF siRNA (AAGAGAAACAGAGAAGAGCCA) and nonfunctional control siRNA (mut siRNA, 5'-AAGAGAAAAAGCGAAGAGCCA-3') were purchased at MWG Biotech (Munich, Germany) or AIF and Bid siRNA mixtures were generated using recombinant dicer enzyme as previously described. ${ }^{8}$ The Bid cDNA template (409 bp) for T7-RNA polymerase in vitro transcription was generated from mouse mRNA by reverse transcription-PCR (RT-PCR) using the following primers: forward, $5^{\prime}$-GCGTAATACGACTCACTATAGGGAGATGGGCTT CTGTCTAAGGAGA-3', and reverse, 5'-GCGTAATACGACTCACTATAGGGAGAA GTGAGGCCTTGTCTCTGAA-3. For the generation of AIF CDNA template, the following primers were used: forward, $5^{\prime}$-GCGTAATACGACTCACTATAGGGAGAT CCAGGCAACTTGTTCCAGC-3' and reverse, 5'-GCGTAATACGACTCACTATAG GGAGACCTCTGCTCCAGCCCTATCG-3'. For siRNA transfections, Lipofectamine 2000 (Invitrogen) and AIF siRNA or nonfunctional mut siRNA were dissolved separately in Optimem I (Invitrogen) and the respective transfection mixtures were added to the antibiotic-free cell culture medium to a final concentration of $20 \mathrm{nM}$ siRNA for dicer products and up to $80 \mathrm{nM}$ siRNA for the single siRNA sequences. Controls were treated with $100 \mu / \mathrm{ml}$ medium only and vehicle controls with $1.5-2 \mu \mathrm{l} / \mathrm{ml}$ Lipofectamine.

Caspase activity measurements. HT-22 neurons cultivated in six-well plates with a density of $4 \times 10^{5}$ cells/well were lysed in $150 \mu \mathrm{l}$ lysis buffer $\left(\mathrm{MgCl}_{2}\right.$ $406.8 \mathrm{mg}$, EGTA $152 \mathrm{mg}$, Triton X-100 $400 \mu$ l, HEPES solution $50 \mathrm{mM} 200 \mathrm{ml}$, Aqua dest. Ad $400 \mathrm{ml})$. Cell membranes were removed by centrifugation at $15000 \times \mathrm{g}$ $\left(15 \mathrm{~min}, 4^{\circ} \mathrm{C}\right)$ and supernatants $(20 \mu \mathrm{l})$ were incubated with $90 \mu \mathrm{l}$ of freshly prepared substrate solution. Fluorescence (excitation $360 \mathrm{~nm}$, emission $465 \mathrm{~nm}$ ) was measured with a SpectraFluor Plus (SpectraFluorPlus, Tecan, Crailsheim, Germany) multiplate reader. Caspase activity was inhibited by using the potent general caspase inhibitor Z-VAD-FMK (R\&D Systems, Wiesbaden, Germany).

RT-PCR. Total RNA was extracted (Nucleospin RNA II kit, Macherey-Nagel, Düren, Germany) and RT-PCR was performed as described. ${ }^{30}$ Primers and PCR conditions for AIF, for example Bid, were the same as given before. Primers for GAPDH were as follows: forward, $5^{\prime}$-CGTCTTCACCACCATGGAGAAGGC- $3^{\prime}$, and reverse, 5'-AAGGCCATGCCAGTGAGCTTCCC-3'. PCR for GAPDH was performed as follows: initial denaturation at $95^{\circ} \mathrm{C}$ for $2 \mathrm{~min}$; amplification by 26 cycles of $30 \mathrm{~s}$ at $95^{\circ} \mathrm{C}, 1 \mathrm{~min}$ at $57^{\circ} \mathrm{C}$, and $2 \mathrm{~min}$ at $70^{\circ} \mathrm{C}$. The final extension was performed at $70^{\circ} \mathrm{C}$ for $10 \mathrm{~min}$. RT-PCR products were visualized under UV illumination after electrophoresis on a $1.5 \%$ agarose gel containing ethidium bromide.

Protein extracts and immunoblots. For western blot analysis, HT-22 neurons were lysed with $50-150 \mu 1$ 1:5 diluted cell lysis reagent $5 \times$ (Promega, Mannheim, Germany), supplemented with 1 tablet per $10 \mathrm{ml}$ Complete Mini Protease Inhibitor Cocktail (Roche, Mannheim, Germany). After centrifugation at $15000 \times g$ for $15 \mathrm{~min}$ at $4^{\circ} \mathrm{C}$, the supernatants were stored at $-80^{\circ} \mathrm{C}$ until further use. Nuclear extracts were separated from cytosolic fractions using the nuclear extract kit according to the manufacturer's instructions (Active Motif, Rixensart, Belgium). Protein amounts were determined with the Pierce BCA kit (Perbio Science, Bonn, Germany).

Western blot analysis was performed as previously described. ${ }^{7}$ Briefly, the blot was probed with an anti-AIF goat polyclonal antibody (sc-9416, 1: 1000, Santa Cruz Biotechnology, Santa Cruz, CA, USA) or anti-Bid monoclonal antibody (611867, $1: 500$, BD Biosciences Pharmingen, Heidelberg, Germany) at $4^{\circ} \mathrm{C}$ overnight. Membranes were then exposed to the appropriate HRP-conjugated rabbit anti-goat or horse anti-mouse secondary antibody $(1: 5000$, Vector Laboratories, Burlingame, CA, USA) followed by a chemiluminescence detection of antibody binding (Spray \& Glow, Millipore, Schwalbach, Germany). Equal protein loading was controlled by re-probing the membrane with a monoclonal anti- $\alpha$-tubulin antibody (T9026, $1: 20000$, Sigma) or an anti-NeuN antibody (mouse monoclonal, 1:100, MAB377, Chemicon/Millipore, Billerica, MA, USA). Scion Image for Windows software (Scion Corporation, USA) was used for quantification of western blot signals.

Statistical analysis. All data are given as means \pm S.D. For statistical comparisons between two groups, Student's $t$-test was used; multiple comparisons were performed by ANOVA followed by Scheffé's post hoc test. Calculations were performed with the Winstat standard statistical software package.

Acknowledgements. The authors gratefully acknowledge outstanding technical support and generation of vectors for transfection experiments by Melinda Kiss as well as additional control experiments by Markus Hofer. This work was supported in part by NIH grant HL082574 to MP.

1. Mattson MP, Duan W, Pedersen WA, Culmsee C. Neurodegenerative disorders and ischemic brain diseases. Apoptosis 2001; 6: 69-81.

2. Culmsee $C$, Landshamer $S$. Molecular insights into mechanisms of the cell death program: role in the progression of neurodegenerative disorders. Curr Alzheimer Res 2006; 3 269-283.

3. Polster BM, Fiskum G. Mitochondrial mechanisms of neural cell apoptosis. J Neurochem 2004; 90: 1281-1289.

4. Yuan J, Yankner BA. Apoptosis in the nervous system. Nature 2000; 407: 802-809.

5. Zhu C, Qiu L, Wang X, Hallin U, Cande C, Kroemer G et al. Involvement of apoptosisinducing factor in neuronal death after hypoxia-ischemia in the neonatal rat brain. J Neurochem 2003; 86: 306-317.

6. Zhu C, Wang X, Huang Z, Qiu L, Xu F, Vahsen N et al. Apoptosis-inducing factor is a major contributor to neuronal loss induced by neonatal cerebral hypoxia-ischemia. Cell Death Differ 2007; 14: 775-784.

7. Plesnila N, Zhu C, Culmsee C, Groger M, Moskowitz MA, Blomgren K. Nuclear translocation of apoptosis-inducing factor after focal cerebral ischemia. J Cereb Blood Flow Metab 2004; 24: 458-466.

8. Culmsee C, Zhu C, Landshamer S, Becattini B, Wagner E, Pellecchia M et al. Apoptosisinducing factor triggered by poly(ADP-ribose) polymerase and Bid mediates neuronal cell death after oxygen-glucose deprivation and focal cerebral ischemia. J Neurosci 2005; 25 10262-10272.

9. Cheung EC, Melanson-Drapeau L, Cregan SP, Vanderluit JL, Ferguson KL, Mclntosh WC et al. Apoptosis-inducing factor is a key factor in neuronal cell death propagated by BAXdependent and BAX-independent mechanisms. J Neurosci 2005; 25: 1324-1334.

10. Heo K, Cho YJ, Cho KJ, Kim HW, Kim HJ, Shin HY et al. Minocycline inhibits caspasedependent and -independent cell death pathways and is neuroprotective against hippocampal damage after treatment with kainic acid in mice. Neurosci Lett 2006; 398 : 195-200.

11. Yu SW, Wang H, Poitras MF, Coombs C, Bowers WJ, Federoff HJ et al. Mediation of poly(ADP-ribose)polymerase-1-dependent cell death by apoptosis-inducing factor. Science 2002; 297: 259-263.

12. Dawson VL, Dawson TM. Deadly conversations: nuclear-mitochondrial cross-talk. J Bioenerg Biomembr 2004; 36: 287-294.

13. Polster BM, Basanez G, Etxebarria A, Hardwick JM, Nicholls DG. Calpain I induces cleavage and release of apoptosis-inducing factor from isolated mitochondria. J Biol Chem 2005; 280: 6447-6454.

14. Plesnila N, Zinkel S, Le DA, Amin-Hanjani S, Wu Y, Qiu J et al. BID mediates neuronal cell death after oxygen/glucose deprivation and focal cerebral ischemia. Proc Natl Acad Sci USA 2001; 98: 15318-15323

15. Becattini B, Sareth S, Zhai D, Crowell KJ, Leone M, Reed JC et al. Targeting apoptosis via chemical design: inhibition of bid-induced cell death by small organic molecules. Chem Biol 2004; 11: 1107-1117.

16. Becattini B, Culmsee C, Leone M, Zhai D, Zhang X, Crowell KJ et al. Structure-activity relationships by interligand NOE-based design and synthesis of antiapoptotic compounds targeting Bid. Proc Natl Acad Sci USA 2006; 103: 12602-12606.

17. Culmsee C, Plesnila N. Targeting Bid to prevent programmed cell death in neurons. Biochem Soc Trans 2006; 34: 1334-1340.

18. Ward MW, Rehm M, Duessmann H, Kacmar S, Concannon CG, Prehn JH. Real time single cell analysis of Bid cleavage and Bid translocation during caspase-dependent and neuronal caspase-independent apoptosis. J Biol Chem 2006; 281: 5837-5844.

19. Konig HG, Rehm M, Gudorf D, Krajewski S, Gross A, Ward MW et al. Full length Bid is sufficient to induce apoptosis of cultured rat hippocampal neurons. BMC Cell Biol 2007; 8: 7

20. Pei Y, Xing D, Gao X, Liu L, Chen T. Real-time monitoring full length bid interacting with Bax during TNF-alpha-induced apoptosis. Apoptosis 2007; 12: 1681-1690. 
21. Frezza C, Cipolat S, Martins de Brito O, Micaroni M, Beznoussenko GV, Rudka T et al. OPA1 controls apoptotic cristae remodeling independently from mitochondrial fusion. Cell 2006; 126: 177-189.

22. Kim TH, Zhao Y, Ding WX, Shin JN, He X, Seo YW et al. Bid-cardiolipin interaction at mitochondrial contact site contributes to mitochondrial cristae reorganization and cytochrome C release. Mol Biol Cell 2004; 15: 3061-3072.

23. Yin XM, Luo Y, Cao G, Bai L, Pei W, Kuharsky DK et al. Bid-mediated mitochondrial pathway is critical to ischemic neuronal apoptosis and focal cerebral ischemia. J Biol Chem 2002; 277: 42074-42081.

24. Bermpohl D, You Z, Korsmeyer SJ, Moskowitz MA, Whalen MJ. Traumatic brain injury in mice deficient in Bid: effects on histopathology and functional outcome. J Cereb Blood Flow Metab 2006; 26: 625-633.

25. Susin SA, Daugas E, Ravagnan L, Samejima K, Zamzami N, Loeffler M et al. Two distinct pathways leading to nuclear apoptosis. J Exp Med 2000; 192: 571-580.
26. Cande C, Vahsen N, Garrido C, Kroemer G. Apoptosis-inducing factor (AIF): caspaseindependent after all. Cell Death Differ 2004; 11: 591-595.

27. Kazhdan I, Long L, Montellano R, Cavazos DA, Marciniak RA. Targeted gene therapy for breast cancer with truncated Bid. Cancer Gene Ther 2006; 13: 141-149.

28. Duvezin-Caubet S, Jagasia R, Wagener J, Hofmann S, Trifunovic A, Hansson A et al. Proteolytic processing of OPA1 links mitochondrial dysfunction to alterations in mitochondrial morphology. J Biol Chem 2006; 281: 37972-37979.

29. Liu Y, Peterson DA, Kimura H, Schubert D. Mechanism of cellular 3-(4,5-dimethylthiazol-2yl)-2,5-diphenyltetrazoliumbromide (MTT) reduction. J Neurochem 1997; 69: 581-593.

30. Culmsee C, Gerling N, Lehmann M, Nikolova-Karakashian M, Prehn JH, Mattson M et al. Nerve growth factor survival signaling in cultured hippocampal neurons is mediated through TrkA and requires the common neurotrophin receptor P75. Neuroscience 2002; 115: $1089-1108$

Supplementary Information accompanies the paper on Cell Death and Differentiation website (http://www.nature.com/cdd) 